\title{
As perspectivas dos outros: uma necessidade na pesquisa em Linguística Aplicada
}

\author{
Rusanil dos Santos Moreira Júnior ${ }^{1}$
}

\section{Resumo}

Este texto aborda, fundamentado nas discussões mais atuais sobre os direcionamentos da pesquisa cientifica na contemporaneidade em Linguística Aplicada (LA), questões relativas à promoção da multiplicidade de olhares ao estudar os fenômenos socialmente relevantes com os quais essa área se preocupa. O objetivo é discorrer, de maneira sucinta, sobre a importância das perspectivas dos outros no processo de construção do conbecimento. Nesse sentido, destacam-se três entre eles: 0 outro-participante, o outro-eu e o outro-teórico. As considerações realizadas neste trabalho não se limitam aos estudiosos que atuam na LA, pelo contrário, elas se estendem a todos aqueles que, independentemente do seu campo de atuação, estudam as relações humanas histórica e socialmente situadas em que a linguagem ocupa lugar central na compreensão delas.

Palavras-chave: Ciências bumanas. Educação. Linguagem. Lingua

\footnotetext{
${ }^{1}$ Professor Substituto de Língua Espanhola da Faculdade de Letras da Universidade Federal de Alagoas (Fale/Ufal). Mestre em Línguistica, com ênfase em Linguística Aplicada.
} 
A área da Linguística Aplicada (doravante LA), que iniciou o seu percurso investigativo em meados da década de 40 no Brasil, ao longo dos anos veio repensando e readequando as suas bases epistemológicas e, consequentemente, metodológicas, com a proposta de refletir sobre o que está desenvolvendo como ciência na contemporaneidade, considerando os aspectos históricos, sociais, políticos, econômicos e culturais nos quais está inserida.

Hoje, inerente e continuamente autorreflexiva e problematizadora (MOITA LOPES, 2006), a LA busca contemplar as perspectivas dos outros, isto é, promover o diálogo, a multiplicidade de olhares ao estudar os fenômenos que pretende questionar, de maneira contextualizada e situada. É sobre essa característica - a importância da visão dos outros no processo de construção do conhecimento - que discorro algumas ideias pertinentes a isso. Com esse objetivo, ressalto aqui três outros significativos: o outroparticipante (sujeito da pesquisa), o outro-eu (presente nela) e o outro-teórico (que pode contribuir com ela).

Ao fazer ciência, do ponto de vista das investigações tradicionalistas, ou seja, da maneira positivista de estudar as relações humanas, somente o olhar do pesquisador é privilegiado e tido como verdadeiro, unânime e determinante no processo de outorgar validez às ideias veiculadas no trabalho, cuja voz de autoridade é revestida por um pseudovéu hermético e enroupada de neutralidade, uma vez que a subjetividade parece ser inconcebível nesse paradigma. Todas as outras vozes, as do contexto teórico-social, as daqueles que contribuíram com o desenvolvimento da pesquisa - e que habitualmente são objeto de estudo -, a título de exemplo, são reiteradamente apagadas, esquecidas ou desconsideradas nas análises. Em desconformidade com esse modo de pesquisar, como a LA tem uma postura imanentemente interpretativista e crítica em busca de compreender e descrever o sujeito social, o qual é dialógico, heterogêneo, fragmentado e fluido (BAKHTIN/VOLOCHÍNOV, 2014; MOITA LOPES, 2006; PENNYCOOK, 2006), é imprescindível que as vozes envolvidas nas práticas sociais em pauta sejam ouvidas e contempladas nesse movimento de geração de conhecimentos.

Sendo assim, o olhar do outro-participante - sujeito da pesquisa - não deve ser visto e utilizado como uma mera confrontação de posicionamentos na tentativa de encontrar uma verdade, como inadequadamente alguns pesquisadores entendem sobre a triangulação de dados na pesquisa qualitativa. Contrário a isso, abraço a ideia de que o linguista aplicado 
deve consultar os participantes do estudo envolvidos - inclusive a si mesmo se participante dele também o for, buscando transitar de modo responsável e fidedigno entre os dois papéis - para que sejam revistas as intepretações por ele realizadas a fim de readequá-las e, sobretudo, compreender melhor esse outro a partir dele mesmo, uma vez que a perspectiva do pesquisador é somente uma das que são possíveis, passíveis de reelaborações e/ou imprecisões. A triangulação de dados, portanto, advém da necessidade de evidências confirmadoras do fenômeno estudado, a partir de múltiplas e diferentes fontes de informação, para "lançar luz sobre um tema ou perspectiva" (CRESWELL, 2014, p. 197). Afinal, as nossas perspectivas são representações parciais do mundo, as quais são ideologicamente orientadas, ou seja, retratam um viés dos eventos em que estamos inseridos e, por isso, não são neutras e refletem apenas um dos pontos de vista existentes (JANKS, 2016).

Apesar disso, como evidencia Kleiman (1998), a LA não vem determinando, pelo menos explicitamente, as diversas perspectivas de seus participantes. Ora, se o compromisso social da LA é contribuir com encaminhamentos de problemas das práticas sociais das pessoas, ou melhor, questioná-los ou até (des-re)construí-los (MOREIRA JÚNIOR, 2016), as pesquisas, por sua vez, devem buscar não somente ouvir essas pessoas ou descrever o que temos a dizer a respeito delas, mas, principalmente, desenvolver contribuições significativas para as suas vidas. É assim, portanto, que emerge um dos fundamentos da pesquisa em LA: a sua relevância social.

Após esses apontamentos sobre o outro-participante na tentativa de esclarecer a sua importância na composição de sentidos, concentremo-nos agora no outro que está presente em nós mesmos - pesquisadores -, principalmente naqueles que analisam as próprias práticas em sala de aula, por exemplo.

Nessa situação, existem, no mínimo, o outro-pesquisador e o outro-professor que coabitam um único ser. Acredito, então, que estão fundidas pelo menos essas duas personagens que precisam ser cuidadosamente consideradas na realização das análises e interpretações das experiências de caráter científico. Esse trânsito de papéis e de olhares deve ser ponderado, afinal, não há entre esses outros uma relação unívoca, mas, sim, conflitante, dialógica (BAKHTIN/VOLOCHÍNOV, 2014), em razão de que, inerentemente, somos seres em constante conflito com as nossas convicções. Com efeito, há um liame entre o conhecer e o querer que não garante o fazer, a harmonia esperável. 
Em outras palavras, os conhecimentos teórico-metodológicos do outro-pesquisador não garantem a sua coerência com as práticas do outro-professor por fatores diversos, que vão desde questões institucionais à dificuldade de desvencilhar-se de velhas práticas. Como argumenta Foucault (PENNYCOOK, 2006), devemos sempre interrogar as nossas próprias maneiras de pensar, as quais, exteriorizadas através do discurso, estão carregadas de ideologias (KUMARAVADIVELU, 2006). Desse modo, faz-se necessária uma postura crítica constante sobre o nosso pensar e agir nas diversas situações e papéis sociais.

Além do outro-participante e do outro-eu, ambos atores sociais imprescindíveis no processo de pesquisa que envolve pessoas, realço neste momento o outro-teórico, isto é, aquele epistemologicamente marginalizado pelos espaços hegemônicos de produção de conhecimentos, quer sejam globais, quer sejam locais. Para isso, fundamento minha posição em Kleiman (2013) e Santos (2010) quando se referem ao Sul, mais precisamente às Epistemologias do Sul, termo cunhado por este teórico. Evidencio, desse modo, a necessidade de considerarmos também os teóricos periféricos, do ponto de vista da produção e disseminação de teorias, que relativamente pouco consubstanciam as pesquisas de seus lugares de produção.

Nessa linha de pensamento, acredito que devamos considerar toda a ecologia de saberes produzidos (SANTOS, 2010) a fim de valorizar, credibilizar e validar os conhecimentos dos estudiosos que não estão no rol eurocêntrico e hegemônico da episteme. Não na tentativa de rechaçar os saberes atualmente privilegiados ou desconsiderá-los; senão, sobretudo, na de contemplar outras vozes, diria eu vozes mais próximas das realidades em que são desenvolvidas as pesquisas. Penso, portanto, que melhor compreendemos a completude - não a totalidade - das relações humanas quando escutamos as vozes locais para tratar de problemas locais. Como assevera Kleiman: "com olhos do Sul, para o Sul” (KLEIMAN, 2013, p. 50).

Considerando a LA uma área que se diz tratar de questões complexas (KLEIMAN, 1998; MOITA LOPES, 2006), uma única voz é inviável, impraticável e inconcebível se o propósito dela é percorrer por essa complexidade que busca entender. Nesse sentido, a valoração dos pontos de vista dos outros, a saber, da miríade de discursos envolvidos de forma pragmática no processo metodológico da pesquisa qualitativa, em que a LA se reconhece, é extremamente necessária na construção da teia de significados que compõem o nosso objeto de estudo: as linguagens (FABRÍCIO, 2006; KUMARAVADIVELU, 2006). 
Diante disso, no decorrer deste breve texto, expus sucintamente a importância da visão dos outros na ampliação de perspectivas, na compreensão da completude dos sentidos produzidos e, consequentemente, na construção de conhecimentos, com o objetivo de fazer-se ouvir as vozes de todos eles. Com esse fim, concentrei-me em três outros: o outroparticipante da pesquisa, extrapolando a visão preeminente do pesquisador no estudo; o outro-eu, reconhecendo a sua alteridade e a necessidade do discernimento de visões entre o pesquisador e o professor em análise, quando são a mesma pessoa; e o outro-teórico, considerando as investigações científicas daqueles estudiosos que não estão no elenco dominante da produção de saberes.

Vale salientar que, apesar de eu ter ressaltado os encaminhamentos dos estudos mais recentes em LA, área na qual atuo, estendo essa necessidade de considerar e integrar esses outros às pesquisas de um modo geral, principalmente àquelas que estão no campo das Ciências Humanas, que trabalham com e por meio das linguagens e que estão mais preocupadas com os processos sociais do que com o produto delas.

O que pretendi sintetizar neste texto, ratifico, é o compromisso de ouvir e valorar as múltiplas e heterogêneas vozes que nos cercam, não com a finalidade de anular as que são hoje preponderantes, nem sobrepor umas às outras, nem tampouco segui-las fielmente como uma nova verdade, mas empoderar as que atualmente estão à margem.

\section{Referências}

BAKHTIN, M. (VOLOCHÍNOV, V. N.). Marxismo e filosofia da linguagem: problemas fundamentais do método sociológico da linguagem. 16 ed. Trad. Michel Lahud e Yara Frateschi Vieira. São Paulo: Hucitec, 2014.

CRESWELL, J. W. Investigação qualitativa e projeto de pesquisa: escolhendo entre cinco abordagens. 3 ed. Trad. Sandra Mallmann da Rosa. Porto Alegre: Penso, 2014.

FABRÍCIO, B. F. Linguística aplicada como espaço de "desaprendizagem”: redescrições em curso. In: MOITA LOPES, L. P. (Org.). Por uma linguística aplicada indisciplinar. São Paulo: Parábola Editorial, 2006.

JANKS, H. Panorama sobre letramento crítico. In: JESUS, D. M.; CARBONIERI, D. (Org.). Práticas de multiletramentos e letramento crítico: outros sentidos para a sala de aula de línguas. Campinas: Pontes Editores, 2016. 
KLEIMAN, A. B. O estatuto disciplinar em linguística aplicada: o traçado de um percurso, um rumo para o debate. In: SIGNORINI, I.; MARILDA, C (Org.). Linguística aplicada e transdisciplinaridade: questões e perspectivas. Campinas: Mercado de Letras, 1998.

Agenda de pesquisa e ação em linguística aplicada: problematizações. In: MOITA LOPES, L. P. (Org.). Linguística aplicada na modernidade recente. São Paulo: Parábola Editorial, 2013.

KUMARAVADIVELU, B. A linguística aplicada na era da globalização. In: MOITA LOPES, L. P. (Org.). Por uma linguística aplicada indisciplinar. São Paulo: Parábola Editorial, 2006.

MOITA LOPES, L. P. Uma linguística aplicada, mestiça e ideológica: interrogando o campo como linguista aplicado. In: (Org.). Por uma linguística aplicada indisciplinar. São Paulo: Parábola Editorial, 2006.

MOREIRA JÚNIOR, Rusanil dos Santos. Português como língua adicional e letramento crítico: ensino-aprendizagem com participantes falantes de outras línguas na Universidade Federal de Alagoas. Dissertação (Mestrado em Letras e Linguística). Maceió: Universidade Federal de Alagoas, 2016. Disponível em:

<http://www.repositorio.ufal.br/handle/riufal/1592>. Acesso em: 23 de Jun. 2018.

PENNYCOOK, A. uma Linguística aplicada transgressiva. In: MOITA LOPES, L. P. (Org.). Por uma linguística aplicada indisciplinar. São Paulo: Parábola Editorial, 2006.

SANTOS, B. A ecologia dos saberes. In: A gramática do tempo: para uma nova cultura política. 3 ed. São Paulo: Cortez, 2010. 


\begin{abstract}
This text, based on current discussions about the direction of scientific studies in contemporary Applied Linguistics, addresses questions related to promoting the multiplicity of points of views when studying social phenomenons. The text's objective is to briefly discuss the importance of perspectives of others when constructing knowledge and highlights three main points: the other participant, the other me and the theoretical other. Its conclusions are not limited to scholars in the field of Applied Linguistics, but in fact the contrary; it expands to all those who, apart from their independent studies, have studied social sciences and are socially situated in which language occupies their primary space of comprehension.
\end{abstract}

Keywords: Humanities. Education. Language

Recebido em: 14/09/2017.

Aceito em: 01/06/2018. 